\title{
El procedimiento coactivo en la legislación ecua- toriana de los últimos años (2005-2018), y su régimen en el código orgánico administrativo
}

\author{
The "coactive procedure" in the ecuadorian legislation \\ of the last years (2005-2018), and its regime in \\ the organic administrative code
}

\author{
Luis Adrián Serrano Chica \\ Investigador Jurídico, Agiltram S.A.
}

Artículo Original (Miscelánea)

RFJ, No. 4, 2018, pp. 107-115, ISSN 2588-0837

RESUMEN: el procedimiento coactivo se refiere a la aplicación de la potestad administrativa respecto de una obligación que los ciudadanos o extranjeros contraen por varias circunstancias en un estado determinado; respecto del procedimiento administrativo, varios cuerpos legales han determinado su estructura y aplicación procesal. El Código Orgánico Administrativo se impone sobre la normativa anterior para regular en la actualidad este procedimiento que merece un análisis retrospectivo respecto del debido proceso, el derecho a la legítima defensa, la seguridad jurídica y sus principios en general, para determinar si ha logrado superar los vacíos procesales y legales que han sido observados en anteriores leyes.

PALABRAS CLAVE: procedimiento coactivo, seguridad jurídica, tutela judicial efectiva, debido proceso, Administración Pública.

ABSTRACT: The coercive procedure refers to the application of the administrative authority with respect to an obligation that citizens or foreigners contract for various circumstances in a given state; Regarding the administrative procedure, several legal bodies have determined its structure and procedural application. The Organic Administrative Code is imposed on the previous regulations to regulate at present this procedure that deserves a retrospective analysis regarding due process, the right to self-defense, legal security and its principles in general, to determine if it has managed to overcome the gaps procedural and legal that have been observed in previous laws. 
KEY WORDS: coercive procedure, legal security, effective judicial protection, due process, public administration.

\section{INTRODUCCIÓN ${ }^{50}$}

Existen obligaciones reconocidas por la ley ecuatoriana (Código Civil del Ecuador, Art. 1435), que los ciudadanos del Estado deben cumplir, por ejemplo en materia tributaria; en caso de inobservancia de esta clase de obligaciones la administración pública tiene mecanismos como el procedimiento coactivo con el cual se encarga de ejecutar forzosamente estos deberes de los mandantes con el Estado pues al contar este con la conocida autotutela administrativa, que se entiende como la capacidad que tiene la administración pública para tutelar por sí misma todo fenómeno jurídico en el cual se vea involucrado el estado (García de Enterría, 2006); tiene legitimidad para aplicar estas medidas.

Lo anterior dicho intenta explicar en concreto el procedimiento coactivo al que la ley faculta a través de sus instituciones para el cobro de toda obligación que los sujetos de derecho no han cumplido a pesar de ser advertidos a través de actos administrativos (Toscano, 2013) y su aplicación (COA, 2018), son precisamente estos parámetros de estructura administrativa las guías necesarias en el momento de iniciar el procedimiento coactivo, además de reconocer cuáles son las especificidades que los empleados recaudadores deben observar.

La legislación ecuatoriana trataba este tema en el ahora derogado Código de Procedimiento Civil determinándolo como una vía para hacer efectivo el pago que se le deba al estado (Código de Procedimiento Civil, 2005), después, en el año 2015 se promulga el Código General de Procesos que se encargó de tratar el procedimiento coactivo hasta la entrada en vigencia del Código Orgánico Administrativo a mediados de 2018.

$\mathrm{Al}$ igual que en los anteriores cuerpos normativos el COA inicia con el reconocimiento de la obligación, reservándose para su ejecución un procedimiento específico y cuyos términos están establecidos, es decir, que no se podrá pedir su tramitación abreviada (COA, Art. 163)

50 Esta nota de revisión fue originalmente elaborada considerando el escenario del Art. 1 de la Ley Orgánica para la Defensa de los Derechos laborales (norma derogada el 21 de agosto de 2018) 
pues los ejecutores son los "empleados recaudadores" a los cuales la ley les otorga la acción coactiva.

El empleado recaudador iniciará el procedimiento coactivo solamente con la orden de cobro, y se valdrá para probarlo de toda constancia en los archivos públicos. En este momento existe previo iniciar el procedimiento, la posibilidad de excusa por parentesco; cualquier impugnación será conocida por la jurisdicción contenciosa administrativa, buscando el objetivo primordial que es el cumplimiento de la obligación (COA, Art. 282) que se lo logra a través del secuestro y embargo de bienes como también por medio de acuerdos de Pago.

El presente trabajo busca plantear ciertas observaciones que podrían afectar ciertos derechos de los ciudadanos del Estado ecuatoriano, como es el del debido proceso, la seguridad jurídica e incluso la tutela judicial efectiva, ya que se piensa que hay una clara inconsistencia con el principio de progresividad del cual en el sentido de aprobación normativa evitan disminuir o limitar derechos sino ampliar el espectro normativo en beneficio de las finalidades estatales y sus ciudadanos (Mancilla, 2015), se espera que las siguientes líneas sirvan para que el autor sea capaz de emitir sus propias conclusiones respecto a esta temática.

\section{DETERMINAR LAS POSIBLES VULNERACIONES A LA SEGURIDAD JURÍDICA, TUTELA JUDICIAL EFECTIVA Y AL DEBIDO PROCESO, RESPECTO DEL COA}

El COA como vía procesal en los procedimientos administrativos tienes como finalidad servir a la colectividad a través de la expedición de una normativa que satisfaga las exigencias con el reconocimiento de ciertos principios (Constitución del Ecuador, 227). Esta ley denomina procedimiento coactivo a esta facultad del Estado que fue conocida anteriormente como juicio coactivo (El Universo, 2013), el nuevo Código para el manejo administrativo del Estado entiende al "Juicio Coactivo" por su naturaleza administrativa, detallando su procedimiento con sus limitaciones y determinando indirectamente la nueva forma de llamar a la exigencia de una obligación dineraria a favor del Estado.

De lo anterior dicho se identifica una acertada conceptualización del procedimiento coactivo como tal, así mismo existía con la legislación anterior un problema, que por ser simple y comprensible no debe pasar 
desapercibido pues el sistema legal debe ser claro y preciso, para no generar controversias innecesarias en el momento de aplicar la norma. Es por esta razón el ejecutor delegado por la institución pública para la cobranza, tomando en cuenta que en el Código Orgánico de la Función judicial, ya no existe el "Juez de Coactiva" (Código Orgánico de la Función Judicial, 2013) en el COA se lo va a denominar como "Empleado Recaudador" al servidor público que forma parte de la función administrativa, logrando con esto eliminar confusiones respecto de los llamados "Jueces de coactiva", que no son más que funcionarios públicos y por lo tanto su naturaleza es administrativa (LOSEP, Art. 4). Una vez aclarados las malas conceptualizaciones del procedimiento coactivo y los servidores públicos que ejecutan o activan la autotutela administrativa se reconoce que un empleado recaudador ejerce su competencia administrativa y busca en cumplimiento de sus funciones hacer exigible la obligación al sujeto pasivo con la finalidad de entregar al Estado lo que le pertenece (que es de todos).

Este problema históricamente se daba cuando el empleado recaudador se extralimita en sus funciones y emite autos de ampliación, con los cuales permiten levantar el velo societario sin probar anticipadamente la responsabilidad, amparándose en el derogado Art. 1 de la "Ley Orgánica para la Defensa de los Derechos Laborales", es precisamente el COA el que debería solventar esta posibilidad en la actualidad junto con la ley orgánica para el fomento productivo, atracción de inversiones, generación de empleo, estabilidad y equilibrio fiscal. Situación en la que excede su competencia administrativa el empleado recaudador y ocasiona una serie de violaciones a la tutela judicial efectiva, al debido proceso y a la seguridad jurídica, además de la responsabilidad limitada.

La tutela judicial efectiva es la posibilidad que tiene la persona de acceder a los órganos jurisdiccionales de justicia, organismos que poseen el monopolio de la administración de justicia y a los cuales se les puede exigir el reconocimiento de un derecho (Enciclopedia Jurídica, 2008), llevar a cabo esta acción tiene como fin impedir la indefensión,

En el párrafo anterior intenta determinar circunstancias donde los empleados recaudadores emplean este artículo (Art. 1 de la Ley Orgánica para la Defensa de los Derechos Laborales), y proceden sin haber sido reconocido por el juez a través de sentencia una defraudación fiscal, puede pedir además medidas precautelares incluso a personas naturales que gozan del respaldo de la responsabilidad limitada, sujetos cuya obligación social responde solo al monto de su aporte individual (Ley de Compañías, Art. 92). 
Si bien existen vacíos que debe suplir el COA, también existen aciertos como una definición exacta de la acción coactiva (Toledo, 2017). Dotando de límites a los empleados recaudadores para alcanzar las medidas cautelares específicas del código, lo cual logra vincular a la competencia judicial las medidas personales permitidas en el COA, de esto es posible tener una idea clara del procedimiento (sumario) que se debe seguir sí se necesita ampliar las medidas cautelares reales a una personal como la prohibición de salida del país.

Dentro del procedimiento coactivo, es la notificación del título de crédito a través de la prensa una de las vías posteriores al Auto de Pago más frecuentes por la cantidad de usuarios a quienes se les reclama el cumplimiento de una obligación. Este acto que cumple con una obligación de dar a conocer a los interesados una resolución recaída en un trámite o en un asunto de carácter judicial (Cabanellas, 2010) y también puede pedir Medidas Cautelares, lo que termina por comunicar al deudor que ha incumplido y se ha iniciado en su contra del procedimiento coactivo (COA, Art. 167).

Sin embargo, el COA solo determina que se publique un extracto del acto administrativo, pero no comunica a la contraparte, quién es el funcionario, ni siquiera los detalles del proceso con el cual el presunto obligado puede reconocer el contenido real del procedimiento que está en su contra, sería ilógico que se pida la publicación del procedimiento completo, pero basta con saber qué institución ha iniciado el procedimiento, quién es el representante legal de la institución a quien se le ha delegado iniciar el procedimiento coactivo y datos relevantes, que le permitan como se dijo anteriormente una perspectiva clara de su situación y como debe responder.

Es decir que, una vez iniciado el procedimiento coactivo, la notificación comunica un procedimiento iniciado (María Laura Valleta, 2007) no solo se da a conocer, sino que emana de una autoridad competente para iniciarlo.

No todo lo que viene en el COA son aclaraciones y vacíos, tiene estructuras jurídicas procesales, como la determinación de términos, es necesario observar que el COA tiene varios principios incluidos en su normativa, y a su vez estos motivan y orientan su razón de ser, uno de estos es el de razonabilidad, este principio se refiere a la motivación de la decisión administrativa, como a observar que la motivación no es suficiente, respecto de este principio el profesor Bidart Cam- 
pos sostiene que «lo opuesto a la razonabilidad es la arbitrariedad" es decir que busca la justicia en el procedimiento judicial (Maldonado Muñoz, 2013), para lo cual también se debe observar un razonamiento completo de las causas que generaron el incumplimiento y la solución para los efectos que se generaron.

Para entender de mejor manera lo anterior expuesto véase por ejemplo la circunstancia de pérdida de trabajo de un usuario que ha solicitado un crédito hipotecario con una entidad financiera pública (propóngase el Banco del Instituto Ecuatoriano de Seguridad Social) y por esta razón no puede cumplir el pago del crédito hipotecario o con las cuotas a favor del BIESS, por lo cual, el fin por el cual el BIESS ofrece créditos de vivienda es la posibilidad de generar vivienda, cuando no paga como castigo dejo sin vivienda a quien incumple, esto es una contradicción en sí misma, lo razonable es no solo permitir acuerdos de pago sino determinar una tabla razonable con el deudor, buscando la oportunidad de permitirle al usuario cumplir con su obligación principal y salvar la obligación accidental.

El COA no precisa una sanción a los funcionarios que permiten se acumulen más allá de los previsto por la ley los términos para iniciar un proceso coactivo, es decir que la burocracia que no es otra cosa que la administración que determina la potestad administrativa (Martínez Castilla, 2016) tiene plazos prestablecidos para proceder una vez que se haya vencido el plazo para el pago voluntario (COA, Art. 279) lo cual en el ámbito social genera que los valores impagos se acumulen por el incumplimiento varios meses, al ver que existen varios meses e incluso años de mensualidades acumuladas, al ejecutar y activar el procedimiento coactivo, se genera un obstáculo económico casi imposible de superar, condenando al deudor a incumplir irremediablemente con su obligación.

Por lo tanto, existe una falta en la responsabilidad de las instituciones públicas (determinadas instituciones) respecto del empleado recaudador, al igual que no existe una sanción en el incumplimiento de períodos que regula la ley al retrasarse en los pagos progresivos que incumple el deudor, visto que no ejecuta o acciona el procedimiento coactivo, por lo cual la acumulación que esto genera crea un sinnúmero de complejidades, que terminan por afectar la posibilidad se solventar la falta en el cumplimiento y la posibilidad continua y obligatoria de mantenerse cumpliendo con la obligación de pagos progresivos. 
En su intervención respecto de las observaciones en el tema coactivo, se refiere diciendo que cuando se le mete la mano con toda la fuerza estatal al ciudadano (Moreta, 2016), observa la imposibilidad de impugnación a los actos administrativos (COA, Art. 263), es tétrico tener que acudir al Contencioso competente sin antes verificar a fondo (esto a través de un artículo de revisión), permitiéndole al presunto deudor aplicar su derecho a la legítima defensa (CE, Art. 76) de la obligación que se le establece vía administrativa y de la cual sufre la fuerza que inmoviliza su libertad financiera y patrimonial.

\section{CONCLUSIONES}

El proyecto normativo que además ahora está vigente para la administración pública y lo que a esta respecta, es conocido como Código Orgánico Administrativo, logra enfrascar en su texto el procedimiento coactivo; sin embargo, padece de irregularidades procesales que pueden atentar contra el derecho a la legítima defensa constitucionalmente amparada, como también al debido proceso.

El legislador no observa en el Código Orgánico Administrativo, ni exige la derogatoria expresa o tácita respecto del Art. 1 de la Ley Orgánica para la Defensa de los Derechos Laborales, con la cual por mucho tiempo el funcionario recaudador ha buscado cumplir con la exigencia de la obligación, sin observar si existe responsabilidad del coactivado o terceras personas naturales o jurídicas, hacia las que se extienden las medidas cautelares. El Código Orgánico Administrativo debe estar a la par con el principio de progresividad, que observa que las nuevas leyes que formen parte del ordenamiento jurídico ecuatoriano, llenes los vacíos preexistentes en la ley, y logre superarlos de manera efectiva, esta observación es expuesta respecto del legislador en primer lugar, y del producto que es el COA.

De lo anterior dicho encontramos estas irregularidades, pues el legislador no ha observado las mismas ni cubre los vacíos legales y procesales que permiten que una ley sea eficaz y aplicable en un ordenamiento jurídico que se va adecuando a las necesidades sociales, al no hacerlo, permite que en un procedimiento coactivo se vulneren derechos, es por esto que se debe reflexionar y exigir que estos temas tratados en esta investigación, sean resueltos, para beneficio de la administración pública y del ciudadano. 


\section{REFERENCIAS BIBLIOGRÁFICAS}

Cabanellas de las Cuevas, G. (2010). Diccionario jurídico. Buenos Aires, Argentina: Heliasta.

El Universo (2013). Juicio de coactiva termina con remate de bienes incautados. Quito, Ecuador: El Universo: https// www. eluniverso .com/ 2003/05/26/0001/9/ AB931502523443E4B1E51071ABFE0205.html

García de Enterría, E. (2006). Curso de derecho administrativo. Buenos Aires, Argentina: La Ley.

Larrea Holguin, J. (2008). Enciclopedia jurídica ecuatoriana: voces de derecho civil. Quito, Ecuador: Fundación Latinoamericana Andrés Bello.

Maldonado Muñoz, M. (2013). El principio de razonabilidad y su aplicación al estudio de validez de las normas jurídicas. Revista de Derecho Ius Humani, $N^{\circ}$ 3, España: Dialnet.

Mancilla Castro, R. (2015). El principio de progresividad en el ordenamiento constitucional mexicano. Revista Mexicana de Derecho Constitucional, $\mathrm{N}^{\circ} 33$, México: Elsevier.

Martínez Castilla, S. (2016). La burocracia: elemento de dominación en la obra de Max Weber. Revista de Derecho y Ciencias Sociales, № 9 , Colombia: Misión Jurídica. http://unicolmayor.edu.co/publicaciones/ index.php/mjuridica/article/view/456

Moreta, M. (2016). Sesión 430 - Código Administrativo. Quito, Ecuador: Asamblea Nacional del Ecuador. https://www.youtube.com/watch?v=b40E5NOo_XE

Toledo, F. (2017). Elementos de la acción coactiva. Colombia, Cali: Doctrina y Ley.

Toscano Soria, L. (2013). Procedimientos administrativos y contenciosos en materia tributaria. Quito, Ecuador: Correo Legal. 


\section{Base Legal}

Código de Procedimiento Civil. Codificación 11 Registro Oficial 58. Honorable Congreso Nacional. Quito, Ecuador 12 de julio del 2005.

Código Orgánico Administrativo. Registro Oficial 31. Asamblea Nacional. Quito, Ecuador. 07 de julio del 2017.

Código Orgánico General de Procesos. Registro Oficial 506. Asamblea Nacional. Quito, Ecuador. 22 de mayo del 2015.

Código Tributario. Registro Oficial 38. Honorable Congreso Nacional. 14 de junio del 2005.

Constitución de la República del Ecuador. Registro Oficial 449. Asamblea Nacional. 20 de octubre del 2008.

Recibido: 10 de junio de 2018

Aceptado: 3 de noviembre de 2018

Luis Adrián Serrano Chica: Investigador Jurídico, Agiltram S.A.

Correo electrónico: luad.777@gmail.com 